RAEIC, Revista de la Asociación Española de Investigación

\title{
Libertad de expresión y lenguaje del odio como un dilema entre libertad e igualdad
}

Freedom and hate speech as a dilemma between freedom and equality

\author{
Pérez de la Fuente, Óscar \\ Universidad Carlos III de Madrid ${ }^{1}$ (UC3M) \\ oscar.perez@uc3m.es
}

Forma de citar este artículo:

Pérez, Ó. (2019). “Libertad de expresión y lenguaje del odio como un dilema entre libertad e igualdad", RAEIC, Revista de la Asociación Española de Investigación de la Comunicación, vol. 6, núm. 12, 5-34.

https://doi.org/10.24137/raeic.6.12.1

\section{Resumen:}

Este artículo analiza los motivos para limitar o no la libertad de expresión en los casos de lenguaje del odio. Existen razones desde la libertad como el miedo a la censura y el respeto por el pluralismo y la autonomía moral. Existen razones desde la igualdad como los daños a personas específicas y a colectivos, y un compromiso con el papel de las minorías en una democracia. La decisión en casos de lenguaje del odio es un dilema entre libertad e igualdad. Ambas tienen buenas razones, pero la cuestión es que cualquier decisión supone sacrificar el otro valor.

\footnotetext{
1 Instituto de Derechos Humanos Bartolomé de las Casas, Departamento de Derecho Internacional, Eclesiástico y Filosofía del Derecho. Universidad Carlos III de Madrid.
}

RAEIC, Revista de la Asociación Española de Investigación de la Comunicación vol. 6, núm. 12 (2019), 5-34 
Palabras clave: libertad de expresión, lenguaje del odio, igualdad, minorías, democracia.

\section{Abstract:}

This article analyses the reasons to restrict or not the free speech in hate speech cases. There are reasons from freedom as the fear of censorship and the respect for pluralism and moral autonomy. There are reasons from equality as the damages for specific individuals and for collectives, and a compromise with the role of minorities in democracy. The decision in cases of hate speech is a dilemma between freedom and equality. Both have good reasons, but the point is that in any decision must sacrifice the other value.

Keywords: free speech, hate speech, equality, minorities, democracy.

\section{EL LENGUAJE DEL ODIO Y ALGUNOS DILEMAS SOBRE SU REGULACIÓN JURÍDICA}

¿Puede el odio ser un delito? ¿Cómo puede el Derecho regular las expresiones del lenguaje del odio? ¿Debe hacerlo? Según la Real Academia el odio es la "antipatía y aversión hacia algo o hacia alguien cuyo mal se desea". Se trata de un sentimiento que puede recibir una calificación moral determinada, pero cabe plantearse si tiene el Derecho una forma adecuada de aproximarse a esta cuestión. En este sentido, es preciso realizar una reflexión sobre los valores y principios que organizan la convivencia que justifican los límites de la intervención estatal. Una primera aproximación sitúa el tema lejos de los sentimientos y la psicología, sino más bien en el ámbito de la libertad de expresión. Este es un derecho fundamental que está en la base de la idea de democracia y, precisamente por este motivo, puede considerarse sospechosa su limitación. Toda sociedad democrática debe plantearse cuales son -si los hay- los límites del discurso público, pero debe ser cuidadosa su justificación por el ineludible compromiso en democracia y pluralismo.

Según una versión extendida, en democracia se puede defender cualquier idea, siempre y cuando no comprometa medios violentos. En la conocida definición de Weber el Estado tiene el monopolio de la violencia legítima. Según esta visión, el Derecho puede 
intervenir cuando el discurso haga apología, incite o promueva el uso de la violencia. Sin embargo, el panorama es más complicado. Puede haber expresiones que no inciten a la violencia, pero que su contenido produzca daño para los miembros de los grupos minoritarios ya que los denigran o los vilipendian. Esto plantea un dilema ya que se está afectando la igual dignidad de los individuos en base a características moralmente arbitrarias, mientras que se debe justificar la relevancia del daño que justifique la intervención estatal. Las expresiones basadas en el racismo, la xenofobia, la misoginia y la homofobia son moralmente reprobables, pero la cuestión es si merecen una sanción jurídica y cuál es el umbral de relevancia y quién lo determina.

Para delimitar conceptualmente el lenguaje del odio se podría describir, como Matsuda, con las características de que es un mensaje de inferioridad, dirigido hacia grupos históricamente oprimidos y es acosante, odioso y degradante (Matsuda, 1988-1989, p. 2357). Desde esta perspectiva, Pareck considera que "el lenguaje del odio estigmatiza a su objetivo adscribiéndole un conjunto de cualidades constitutivas que son vistas de forma extendida como altamente indeseables. Como las cualidades adscritas están fuertemente desaprobadas, sus poseedores son despreciados, degradados, considerados como no bastante normales, tratados con desprecio, incluso demonizados. Como las cualidades están con frecuencia presentadas como inherentes en el grupo y por tanto consideradas ineliminables, esto último es considerado como incapaz de reforma o cambio y sus miembros son todos permanentemente condenados". Las consecuencias del lenguaje del odio afectan a las relaciones de los miembros de las minorías con el resto de la población. En este sentido, Pareck afirma que "el grupo elegido es situado fuera de lo tolerable en las relaciones sociales normales. No se puede confiar para observar las reglas gobernando la sociedad, entrar en relaciones significativas con otros miembros de la comunidad, mostrar lealtad a las instituciones y prácticas sociales compartidas, y es en general considerado como una presencia hostil e inaceptable. Por tanto, puede ser legítimamente exterminada, expelida, discriminada, o a lo mejor tolerada como un inevitable mal sobreviviendo en los márgenes de la sociedad" (Pareck, 2006, p. 214). 
¿Es posible concebir un derecho a la injuria colectiva? ¿Puede considerarse que la expresión de los estigmas, prejuicios y estereotipos sobre un colectivo se convierta en una acción punible? Desde un análisis de los grupos oprimidos, Young considera que el racismo, el sexismo, la homofobia y la discriminación en razón de la edad o la discapacidad provocan comportamientos, imágenes, estereotipos que están generalizados, son sistemáticos y se generan y refuerzan mutuamente. Cambiar los hábitos que generan opresión sólo puede acontecer si los individuos adquieren conciencia de sus hábitos individuales y los cambian. Esta es la revolución cultural. Concluye Young que a veces tal cambio puede verse facilitado por la sanción de ciertas leyes o a la implementación de políticas. Sin embargo, la mayor parte de los cambios culturales no pueden llevarse a cabo por ley (Young, 2000, p. 255). Desde esta perspectiva, el Derecho puede ser un mecanismo para que los individuos "tomen conciencia" de su abyección a las minorías, pero no el único ya que se trata de una revolución cultural que, para Young, se basa en que el significado emancipador de la diferencia forme parte de la lucha política.

Quizá los miembros de las minorías otorguen un papel destacado al activismo político para conseguir sus objetivos, pero, desde otro punto de vista, se pueden plantear que de lo que se trata es de dirimir con qué derechos cuentan realmente. No se trata de una mera cuestión de empowerment de las minorías, sino más bien de las reglas de la democracia, de los límites del pluralismo. Lo que caracteriza los casos de lenguaje del odio es que se trata de un dilema entre valores constitucionales. La solución elegida comportará la renuncia a un valor relevante, en lo que se conoce como tesis de mal inevitable. Desde esta perspectiva, se desarrollará más extensamente algunas formas de aproximarse a esta cuestión que Sadurski enuncia (Sadurski, 1999, p. 181):

El primer dilema es entre libertad e igualdad. El primer elemento hace referencia a que libertad de expresión de los individuos es un elemento relevante de desarrollo de su autonomía moral (Mill, Milton), un requisito fundamental de la democracia y un elemento relevante de una sociedad pluralista. El segundo elemento esta relacionado con la consideración sobre la posible exclusión de los 
grupos victimizadas de la vida pública establecida como resultado estereotipos y prejuicios promovidos por el lenguaje del odio.

Lo que el lenguaje del odio deniega es la igual participación de los miembros de las minorías en la democracia, este será un argumento que desarrolla más adelante Fiss.

El segundo dilema tiene que ver con la igualdad formal y la igualdad sustancial. Desde la primera perspectiva, existe un derecho igual a hablar sobre asuntos de pública consideración a pesar de la valía de las visiones de uno. Esto está relacionado, por un lado, con la idea de que el Estado no debe intervenir para limitar la libertad de expresión en lo que se conoce como la visión del mercado de las ideas y, por otro lado, con la doctrina de la Corte Suprema norteamericana que, consiguientemente, considera que el Estado debe ser neutral sobre el contenido de la expresión. La segunda perspectiva, afirma la igualdad sustancial, que implica consideración sobre la igual dignidad de aquellos a los que hiere el lenguaje del odio. Esta visión se aproxima más a la perspectiva alemana de la cuestión ya que la Ley Fundamental de Bonn en su artículo 1 declara la dignidad humana como intangible y la jurisprudencia del Tribunal Constitucional Federal ha interpretado que este valor es prioritario a la libertad de expresión.

El tercer dilema se relaciona con la deferencia hacia la mayoría o el respeto de las minorías. El primer elemento tiene que ver con las opiniones de la mayoría que se ve imperturbada por el lenguaje ofensivo de algunos extremistas. Esto parte de la idea de que, aunque a la mayoría le disguste el discurso de algunas minorías, no es motivo para silenciarlo ya que se realiza una analogía entre el disidente y el racista. El segundo elemento comprende el respeto por los intereses de las minorías que demanda protección de las sensibilidades de los grupos vulnerables. Esto significa reconocer el daño que suponen los ataques a los miembros de las minorías y la necesidad de intervención estatal.

Se ha adoptado la denominación de tragedias constitucionales cuando se producen conflictos genuinos entre derechos fundamentales. Atienza ha propuesto considerar caso trágico a aquella situación en la que no puede alcanzarse una solución que no vulnere un elemento esencial de un valor considerado como fundamental desde el 
punto de vista jurídico y/o moral (Atienza, 2002, p. 201). Esto supone que haga lo que haga el agente, no se evitará un mal. Es lo que se denomina inescapable wrongdoing o tesis del mal inevitable (Lariguet, 2008, p. 57). La alternativa sacrificada queda como un "residuo" y "recordatorio" de que se hizo algo malo (Lariguet, 2008, p. 151). Lo que plantea los casos del lenguaje del odio, si se toman en serio los argumentos expuestos en los dilemas precedentes, es que las soluciones que se pueden proponer tienen algo de caso trágico, lo que les acerca a la noción de auténticos dilemas morales.

Permitir o suprimir el lenguaje del odio supone renunciar a valores relevantes. Desde esta visión, Massaro considera que se trata de un dilema filosófico más general que intenta reconciliar las reivindicaciones competitivas de contingencia y solidaridad, que suponen desacuerdos en la consideración del significado constitucional de la igualdad, el adecuado papel del gobierno para inculcar valores y el significado social y constitucional de la identidad de grupo versus la personalidad individual (Massaro, 1990-1991, p. 214). Los desacuerdos en estos asuntos son relevantes ya que implican concepciones distintas del Derecho y en la jerarquía de los valores constitucionales. En las sociedades democráticas pueden coexistir personas con perspectivas distintas sobre estas cuestiones, pero lo relevante es que, en algún momento, toda sociedad debe tomar decisiones que afectan a la justificación de los límites del discurso. En el caso del lenguaje del odio ${ }^{2}$ ese ejercicio de ponderación muestra cómo la libertad y la igualdad tienen buenas razones y la decisión final, en todo caso, supondría renunciar a un valor relevante. Estas son las dimensiones del dilema ${ }^{3}$.

\section{LOS ARGUMENTOS DE LA LIBERTAD}

La autonomía individual se desarrolla, entre otros ámbitos, a través de la libertad de expresión. La democracia se basa en un debate libre de las ideas que se contrastan en

\footnotetext{
${ }^{2}$ Algunos ejemplos de lenguaje del odio que ofrece Parekh son: “a) Niggers volved a casa. Hacer ruidos de mono o gritar eslóganes racistas en los partidos de futbol. b) Islam fuera de Gran Bretaña. c) Arabes fuera de Francia. d) Sirve a tu país quema una Mezquita e) Los negros son inherentemente inferiores y predispuestos a actividades criminales y no debe ser permitidos en barrios respetables f) Los judíos son conspiradores, arteros y quieren apoderarse del país" (Parekh, 2006, p. 214).

${ }^{3}$ Para abordar la cuestión se centrará la aproximación en la bibliografía anglosajona, especialmente norteamericana, debido fundamentalmente a que esta cuestión ha merecido especialmente la atención de esta doctrina. Esto se debe a que la Corte Suprema ha sido reticente a regulaciones estatales de la libertad de expresión y lo que ha llevado a numerosos autores ha argumentar a favor de las razones de la igualdad en los casos de lenguaje del odio frente a las razones de la libertad. La rigurosidad, riqueza y profundidad de este debate en el contexto norteamericano, permite reflexionar sobre esta cuestión con repercusiones más allá de aquellas fronteras.
} 
la deliberación de los asuntos públicos. El pluralismo es un valor que supone la convivencia de personas que expresan valores divergentes sobre las concepciones de la vida. El compromiso público con la autonomía, la democracia y el pluralismo configuran un papel destacado para la libertad de expresión. Desde este punto de vista, existe una fuerte predisposición contra la censura. El espectro del macarthismo como una "caza de brujas" estatal dirigida a suprimir puntos de vista no favorables está presente. En este sentido, la filosofía que está detrás de la interpretación predominante de la libertad de expresión en Estados Unidos está cercana a la idea de libertad negativa, que explicó Berlin, como no interferencia estatal. Esto significa que como explicaba el juez Holmes por perniciosa que una idea pueda parecer, su corrección depende, no de la conciencia de los jueces y jurados, sino la competición con otras ideas. ${ }^{4}$ Es lo que se conoce como mercado de las ideas que es la interpretación jurisprudencial de la Primera Enmienda que establece que "el Congreso no hará ninguna ley recortando la libertad de expresión o de la prensa". Algunos han querido concebir que la libertad de expresión es un derecho absoluto, sin embargo los desarrollos posteriores de la Corte Suprema aunque le otorgan un papel preponderante, también le impone algunos límites.

Otra de las influencias destacadas sobre la interpretación norteamericana de la libertad de expresión se debe a John Stuart Mill (Hylton, 1996, pp. 119-157; Brink, 2001, pp. 119157). En su ensayo Sobre la libertad establece los principios del individualismo ético que se vinculan con la noción de autonomía. Realiza una fuerte defensa de la libertad de expresión que se justifica en la falibilidad de las opiniones y el peligro de ser silenciadas las consideradas como equivocadas (Stuart Mill, 1999, pp. 135-136). En este sentido, afirma que "si toda la especie humana no tuviera más de una opinión contraria, no sería más justo que la humanidad impusiera silencio a esta sola persona, que si ésta misma, si tuviese poder suficiente para hacerlo, lo ejerciera para imponer silencio al resto de la humanidad" (Stuart Mill, 1991, p. 87). Su posición es una defensa de la heterodoxia y contra el dogmatismo. Además sostiene el conocido principio que justifica la

${ }^{4}$ Gertz v. Robert Welch Inc. 418 U.S. 323, 339-40 (1974) citado por (Ingrer, 1984, p. 7 nota 25). 
intervención estatal cuando un individuo produzca daño a terceros. Su propio bien, sea físico o moral, no constituye justificación suficiente (Stuar Mill, 99, pp. 74-75).

Este es un principio clásico del liberalismo. Obviamente la clave es cómo se define el daño. Lo relevante es que la Corte Suprema ha ido desarrollando una doctrina sobre la libertad de expresión coherente con este principio la intervención estatal en el daño a terceros. Su interpretación ha sido restrictiva en el sentido que ha considerado daño como sinónimo de previsible violencia o incitación a la violencia y, desde la perspectiva acomodacionista, se critica que pueden existir otros daños relevantes asociados a las expresiones de odio.

La libertad de expresión, según la Corte Suprema, tendría límites ya que se debe superar el test del daño presente y claro, como cuando, según el juez Holmes, alguien grita falsamente "fuego" en un teatro lleno de gente, causando pánico. ${ }^{5}$ Una aplicación de este test fue el caso Branderburg, en el que el Ku Klux Klan, que llamaba públicamente a la expulsión de los afroamericanos y los judíos de los Estados Unidos utilizando expresiones como: "es posible que se deba realizar alguna venganza"; "los niggers deben volver a Africa, los judíos volver a Israel.", que debemos "enterrar los niggers". ${ }^{6}$ En palabras de la Corte, "las garantías constitucionales de la libertad de expresión y la prensa libre no permiten al Estado prohibir o proscribir la defensa del uso de la fuerza o la violación de la ley, excepto cuando esa defensa está dirigida a incitar o producir una acción ilegal inminente o es probable que incite o produzca esa acción"7 Es destacable que este es un caso de lenguaje del odio, que no incita claramente a la violencia, pero denigra a los miembros de las minorías.

Más adelante, la Corte Constitucional incorporó la doctrina de las fighting words, que podría traducirse como palabras belicosas, provocadoras o que agreden, que sería un tipo de expresión que no merecería protección constitucional. Se utilizó en el caso Chaplinsky donde un Testigo de Jehová que había estado distribuyendo panfletos religiosos y tuvo un altercado, se dirigió al jefe de la policía en estos términos: "eres un

\footnotetext{
${ }^{5}$ Abrams v United States, 250 U.S. 16, 630 (1919) (Holmes, J. dissenting) citado por (Rosenfeld, 2003, p. 18).

${ }^{6}$ Nigger es una expresión abiertamente racista para referirse a las personas afroamericanas. (Abrams, 1992, p. 747)

${ }^{7}$ Branderburg v. Ohio 395, US 444 (1969) 447 citado por (Abrams, 1992, p. 747).
} 
mafioso condenado por Dios" y "un condenado fascista y el gobierno entero de Rochester son fascistas o agentes de fascistas". ${ }^{8}$ Según la Sentencia, las palabras belicosas son aquellas "(1) que su emisión inflige un daño o (2) tienden a incitar a una inmediata ruptura de la paz", lo que se traduce por producir desórdenes públicos. La Corte Suprema aplicó el segundo significado de las palabras belicosas coherente con su concepción del daño como violencia previsible. Sin embargo, se podría desarrollar una interpretación conforme al significado de las palabras belicosas como aquellas que su emisión inflige un daño que incorporara expresiones de odio contra los miembros de las minorías, como reivindica la perspectiva acomodacionista.

Desde la perspectiva norteamericana, el Estado debe permanecer neutral respecto del contenido de la expresión. Aunque el lenguaje resulte ofensivo, no es el juez el encargado de valorarlo, sino la competición con otras ideas. Tampoco se admiten regulaciones estatales que prohíban un tipo de expresión basadas en el contenido. Precisamente se ha producido un intenso debate sobre las regulaciones de los códigos antirracistas en los campus universitarios. Uno de los argumentos más utilizados, en este contexto, es que la prohibición de determinadas expresiones supondría una pendiente resbaladiza que acabaría por comportar una irrazonable represión de la "buena expresión" (Massaro, 1990-1991, p. 219). Como se pregunta Hemmer: ¿puede una política establecer un límite suficiente? (Hemmer, 1995, p. 311). Por tanto, se debería justificar lo distintivo del lenguaje del odio frente a otro tipo de expresiones ofensivas. También delimitar la diferencia entre el racista y el disidente, que sostendría puntos de vista incómodos para la mayoría. Por último, se debería trazar la línea de la expresión prohibida por odio, pero como sostiene este argumento, cabe plantear que esto suponga un ejercicio interpretativo producto de una ponderación caso a caso y no siempre podría tener éxito en esta tarea.

\footnotetext{
${ }^{8}$ El relato que ofrece Lawrence es el siguiente: “Chaplinsky, un Testigo de Jehová había estado distribuyendo literatura religiosa en la calles de Rochester, New Hampshire, en una concurrida tarde de sábado. Una resentida multitud se congregaba alrededor de Chaplinsky, y un jefe de policía municipal llego a la escena diciendo que Chaplinsky podía distribuir sus panfletos pero advirtiendo a Chaplinsky que la multitud estaba resentida y que seria mejor ir despacio. Un tiempo después, ocurrió un disturbio y Chaplinsky fue escoltado por un oficial de policía a la comisaría. En la ruta, Chaplinsky encontró al jefe de la policía y le dijo "Eres un mafioso condenado por Dios" y "Un condenado fascista y el gobierno entero de Rochester sois fascistas o agentes de fascistas" Chaplinsky v. New Hampshire315 US 5681942 citado por (Lawrence, 1992-1993, pp. 706-708).
} 
Desde la perspectiva de la óptica de Mill, Hemmer plantea en los casos de lenguaje del odio la cuestión de cómo prueba una víctima el daño específico que alega, y más allá, cómo demostrar que el daño es el resultado directo de una particular instancia de lenguaje del odio más que el efecto acumulativo en una vida de comentarios discriminatorios (Hemmer, 1995, p. 311). Según el argumento libertario, el daño que produce el lenguaje del odio es menor que el daño de suprimir la expresión. Este discurso funcionaría como una especie de "válvula de presión" (Delgado, Stefanic, 19951996, p. 475) donde permitiendo este leguaje rencoroso se desactivaría o agotaría la hostilidad a través de la expresión, más que en la violencia física (Massaro, 1990-1991, p. 219) Además como afirma Massaro, la gente, en las naciones que han adoptado leyes de lenguaje del odio, no se ha convertido en menos racistas. Es más, silenciando a los intolerantes, envía a la intolerancia a la clandestinidad y da a los intolerantes un estatus de mártir para explotar. (Massaro, 1990-1991, p. 247).

Lo que lleva al argumento de que es "más expresión" (Delgado, Stefanic, 1995-1996, p. 475), y no su supresión, lo que permite luchar contra el racismo y otras formas de intolerancia. Un manual actualizado de biología pone en evidencia que los principios que subyacen a la ideología racista están refutados científicamente. De hecho, las expresiones de odio retratan de tal forma la personalidad de sus autores que los ponen en evidencia frente al resto de la sociedad, que siempre puede encontrar ideas mejores. Esta última afirmación se puede sostener si se parte de la base de que los individuos están suficientemente capacitados para calibrar la calidad del discurso y nadie por ellos deba realizar está operación de forma paternalista. Lo que plantea la cuestión en términos del papel de los derechos humanos en la educación para la autonomía individual.

Desde la perspectiva del liberalismo, Dworkin sostiene que no podemos reconocer un derecho al respeto, sin subvertir completamente los ideales centrales de la cultura de independencia y negando el individualismo ético que la cultura protege. Opiniones populares y prejuicios de cualquier sociedad serán siempre hirientes para algunos de sus miembros. Gente de miles de diferentes convicciones o valores o gustos comprensiblemente se sienten ridiculizados e insultados por cada nivel de discurso y 
publicación en cada democracia decente en el mundo (Dworkin, 1996, p. 259-260). En esta línea, Rico afirma que "el día que leí que a Bugs Bunny le habían censurado por llamar "tonto" a un esquimal comprendí que estábamos perdidos. "Contenido racial ofensivo", esgrimió la cadena de dibujos animados". ${ }^{9}$

\section{EL CAPITAL ECONÓMICO Y EL CAPITAL SIMBÓLICO}

Los igualitarios abogan, explica Massey, por la supresión del contenido del lenguaje del odio ya que el daño resultante del lenguaje del odio es casi siempre suficientemente grave para ser mayor que el daño resultante de su supresión (Massey, 1992-1993, p. 106). Esta perspectiva se basa en una interpretación radical de los derechos civiles que critica abiertamente el individualismo preponderante en la versión mayoritaria de la libertad de expresión. Por su parte, los acomodacionistas, según Massaro, aprueban, ajustadamente redactadas, medidas cautamente progresivas que tienden a prohibir sólo el vilipendio dirigido a una persona sobre la base de la raza, el género, religión, origen étnico, orientación sexual, u otras características protegidas (Massaro, 19901991, p. 213). Desde esta visión, se invoca la doctrina de las palabras belicosas, pero con una vuelta. En este sentido, argumentan que la Corte debe extender la doctrina de las palabras belicosas para incluir epítetos que son dirigidos generalmente a todos los miembros del grupo, en la teoría que esa expresión asimismo inflinge daño y amenaza la paz social y la paz mental de los miembros del grupo. ${ }^{10}$ Se debe recordar que la doctrina la las palabras belicosas surge en el caso Chaplisnky y que la Corte Suprema limita su significado a aquellas que pueden causan desórdenes públicos. ${ }^{11}$ Otra perspectiva en esta línea, es la propuesta de Delgado de utilizar el derecho de responsabilidad civil "tort law" para demandar a los que realicen insultos racistas (Delgado, 1982, pp. 159-181). La perspectiva acomodacionista parte del actual

\footnotetext{
${ }^{9}$ Continúa afirmando Rico “ignoro cuántos esquimales se sentirían ultrajados por las bromas de un conejo idiota." (Rico, 2004, p. 14).

${ }^{10}$ Continúa afirmando Massaro que "Ellos niegan que la probable represalia física sea el principio adecuado para medir la aceptabilidad de los insultos. De hecho, una respuesta tipo "luchar o huir" debe ser la medida, en reconocimiento que las represalias físicas no son una respuesta natural o prudente para muchos miembros de los grupos marginados. "Huir" se refiere tanto a la retirada física y a la reacción emocional adversa a un ataque verbal” (Massaro, 1990-1991, pp. 232-233).

11 Un ejemplo de la doctrina acomodacionista sería Regulación de Stanford que prohibiría la expresión que: a) Pretende insultar o estigmatizar individuos sobre la base de características protegidas b) Está "dirigida directamente" a aquellos insultados o estigmatizados y c) Realiza un uso de las "palabras belicosas" o insultantes como aquellas palabras que "por su mera emisión infligen un daño o tienden a incitar un inmediata ruptura a de la paz" (Massaro, 1991, p. 252).
} 
paradigma jurídico para encontrar mecanismos que regulen el lenguaje racista, mientras la visión igualitaria se cuestiona las bases del paradigma jurídico. ${ }^{12} \mathrm{~A}$ continuación se detallarán algunas justificaciones más habituales a favor de regular las expresiones del lenguaje del odio. No todas están al mismo nivel. Algunas inciden en las consecuencias indeseables de este discurso mientras otras se refieren a su naturaleza, como lenguaje irracional o malo intrínsecamente., cristalizado.

\subsection{EL ARGUMENTO DEL DAÑO A INDIVIDUOS ESPECÍFICOS}

El lenguaje del odio produce víctimas e inflinge un daño a los individuos contra los que se dirige. Como destaca Delgado, "la inmediata angustia mental o emocional es el más obvio daño directo por un insulto racial. Sin cuestión, las meras palabras, ya sean raciales o de otro tipo, pueden causar daño mental, emocional e incluso físico a su objetivo, especialmente si son pronunciadas en frente de otros, o por una persona en posición de autoridad (Delgado, 1982, p. 143). Pero, añade Delgado, la atrocidad mayor del insulto racial es que es una ofensa a la dignidad, una directa violación de derecho a la víctima a ser tratada respetuosamente (Delgado, 1982, p. 143).

En un ensayo titulado Cómo hacer cosas con palabras, Austin propone la distinción entre actos ilocucionarios y actos perlocucionarios, y se pueda afirmar que existen actos de habla que producen ciertos efectos. ${ }^{13}$ Como afirma Saavedra "donde más claramente parece el carácter performativo que a veces adquiere el lenguaje es el insulto. Que el lenguaje tiene un carácter performativo, o realizativo, significa precisamente que es una forma de acción. Las palabras cambian el mundo, y no sólo porque provoquen mediante la información o los argumentos una toma de posición capaz de llegar a la acción sino, porque, mediante su pronunciación, pueden crear algo que antes no existía." (Saavedra, 2006, p. 569). En este sentido, Butler afirma que los enunciados de lenguaje del odio forman parte de un proceso continuo e ininterrumpido al que estamos sujetos, una sujeción (assujetissement) constante que es la operación misma de la interpelación, esa

\footnotetext{
12 Los actos ilocucinarios son actos de hala que cuando dicen algo hacen lo que dicen. (Butler, 2009, p. 18).

13 Los actos ilocucinarios son actos de hala que cuando dicen algo hacen lo que dicen. Lo a actos de habla perlocucionarios son actos de habla que producen ciertos efectos. A estos últimos también se incluyen en lo que denomina la función preformativa del lenguaje (Butler, 2009, p. 18; Autin, 2017).
} 
acción repetida a través de la cual los sujetos son constituidos en la subyugación. Estos términos ofensivos que señalan un espacio discursivo de violación preceden y ocasionan el enunciado que nos representa; el enunciado es la ocasión de renovar esa operación de interpelación (Butler, 2009, p. 53). Como somos seres lingüísticos, Saavedra considera que el insulto $-y$ el lenguaje del odio en tanto que insulto- es un acto que extrae su fuerza de ese carácter dependiente del lenguaje que tiene todo sujeto. Y por eso es por lo que este tipo de lenguaje puede ser un acto de agresión y de violencia en sí mismo (Saavedra, 2006, p. 570).

\subsection{EL ARGUMENTO DEL DAÑO A GRUPOS ESPECÍFICOS}

Los teóricos de los derechos civiles argumentan, para Massaro, que cuando el gobierno no regula el lenguaje del odio, se presta a agresiones a los valores expuestos de Brown v. Board of Education. La omisión, en este caso, es comisión. La violación de los derechos civiles está conectada con el gobierno y es un asunto de un momento constitucional. (Massaro, 1991, p. 240). La interpretación tradicional de la Corte Suprema norteamericana sobre libertad de expresión aboca a una tragedia constitucional, en el sentido, que el método favorecido de interpretación constitucional produciría resultados lamentables. ${ }^{14} \mathrm{El}$ principio antisubordinación que impide que se forme una sociedad de castas, que se expone en el mencionado caso Brown, muestra cómo la Constitución no es neutral en valores y, más allá, que frente a la pretensión que la Primera enmienda sobre libertad de expresión es absoluta, podría argumentarse que debería darse más peso a la Decimocuarta Enmienda con la clausula de igualdad.

Un compromiso estatal con la lucha contra el racismo, desde esta perspectiva, debería comportar algunas restricciones a la libertad de expresión. Esto puede suponer una interpretación más amplia del individualismo, basada en consideraciones en función de la pertenencia grupal. Desde esta perspectiva, existiría una fuerte vinculación entre el racismo y el discurso racista debido a que, según Matsuda, el racismo "es la subordinación estructural de un grupo basada en la idea de inferioridad racial. El

\footnotetext{
${ }^{14}$ Balkin continúa firmando que "o bien, que la Constitución permite o requiere injusticias serias y profundas, como la esclavitud" (Balkin, 1998, p. 121).
} 
discurso racista es particularmente dañino porque es un mecanismo de subordinación, reforzando la relación vertical histórica" (Matsuda, 1989, p. 2358).

El lenguaje del odio va contra la igual dignidad de los miembros de los grupos vulnerables. Suponen un refuerzo de estigmas, prejuicios y estereotipos sobre la identidad de los grupos, que dificultan el respeto y la consideración con los otros medios de la sociedad. Pero quizá el mecanismo más perverso del lenguaje del odio es que puede generar auto-odio. Es decir, que los miembros de las minorías internalizan los argumentos negativos sobre ellos. Como afirma Matsuda, "para la victima, el airado rechazo de mensaje de inferioridad esta conectado con la absorción del mensaje." (Matsuda, 1989, p. 2340). Este sería uno de los efectos más devastadores del lenguaje del odio.

\subsection{EL ARGUMENTO DE LA EXCLUSIÓN DE LAS MINORÍAS DEL DISCURSO PUBLICO}

Una interpretación interesante del papel de la igualdad en la argumentación del lenguaje del odio la ofrece Fiss cuando centra la cuestión en las precondiciones necesarias para el autogobierno y el debate público, donde se debería asegurar que todas las visiones sean presentadas, pero las regulaciones del lenguaje odio se basan en la idea de que en ocasiones es necesario disminuir las voces de unos para que pueda ser escuchada la voz de otros (Fiss, 1996, p. 23). Esto supone que el debate de la igualdad sobre la libertad de expresión se traslade de la Decimocuarta Enmienda, a la Primera Enmienda. En este sentido, Fiss afirma que la preocupación, no es si las expresiones objeto de regulación estatal- lesionan o no el estatus social de ciertos grupos, sino la demanda de esos grupos, por tener una oportunidad plena y equitativa para participar en el debate público: lo que importa es la demanda de su libertad de expresión. ${ }^{15}$ Esto supone que el debate público debe garantizar la igual participación de los miembros de las minorías aportando sus puntos de vista, que se verían dificultadas si se admiten las visiones estigmatizantes que los ponen en cuestión. En ese caso, la Corte debe

\footnotetext{
15 Fiss continúa afirmando que “Más aún, el Estado honra esas demandas no por su valor intrínseco o por el mérito de las perspectivas que plantean, ni porque el derecho de expresión de uno sea superior al de otros, sino sólo porque debe preservar la apertura e integridad del debate público. Lo que motiva la acción del Estado no es tanto el interés de los individuos por expresarse, sino el interés de la audiencia -la ciudadanía- por escuchar un debate pleno y abierto de los asuntos de importancia pública" (Fiss, 1996, pp. 23-24).
} 
preguntarse: ¿amplía realmente la intervención la calidad del debate o tienen acaso el efecto opuesto? (Fiss, 1996, p. 27).

Un argumento en contra lo ofrece Post que considera, aunque censurar el discurso racista es consistente que el principio sustancial de igualdad, es inconsistente con el principio formal de igualdad porque esa censura excluye del publico discurso aquellos que no están de acuerdo con un forma sustantiva particular de igualdad (Post, 19901991, p. 304). En una línea de crítica similar, Massey expresa un argumento contra el papel de la igualdad en el contexto de la libertad de expresión. La garantía de la libertad de expresión afirma el derecho igual de cada persona de participar en el discurso público. Limitar el discurso público por una apelación a la igualdad es afirmar que existe una dimensión sustantiva de igualdad, que triunfa incluso el derecho de la gente de gobernarse a si mismo. Si esto es así, los parámetros de esta igualdad sustantiva deben ser determinados por alguien. Pero la gente no puede hacer esto legítimamente, por su autonomía ha sido restringida por la incursión en el discurso publico demanda en el nombre de la igualdad sustantiva. ¿Quién, entonces, decide? ${ }^{16}$

La ventaja del planteamiento de Fiss es que precisamente sitúa la cuestión en la autonomía igual para todos en participar en el debate público y lo que le corresponde al Estado el asegurarse de su participación y eliminar la exclusión del debate a los puntos de vista de las minorías. Esto supone silenciar algunas voces porque no respetan las reglas del debate. Esas voces no respetan la autonomía de los demás y realizan un discurso que no tiene valor ya que no aumenta la calidad del debate y produce daño ya que denigra, vilipendia o estigmatiza a los miembros de las minorías. Desde este punto de vista, Parekh afirma que lejos de limitar la autonomía, esa ley crea las condiciones para ella. Desde que los grupos vulnerables están interesados, se salvaguarda su autonomía protegiéndolos contra un clima de acoso e intimidación (Parekh, 2006, p. 221).

\footnotetext{
${ }^{16}$ Massey concluye su visión "El argumento de la igualdad sustantiva es casi imposible de lograr y si se cumple, irremisiblemente inutiliza el principio de autonomía que es el fundamento del autogobierno" (Massey, 1992-1993, p. 174).
} 
El argumento sobre la igual participación supone que las condiciones de la democracia excluyen los que no respetan las condiciones del debate público, que incluyen la igual participación de todos los puntos de vista. La deliberación de los asuntos públicos, según Sunstein, se debería basar en los valores de igualdad política, universalismo e imparcialidad (Sunstein, 1987-1988, p. 1552). Es difícil considerar que aportan para la calidad democrática las visiones que sistemáticamente niegan esos valores. Como sostiene Parekh, la libertad de expresión es ciertamente el elemento vital de la democracia, pero es difícil ver como el lenguaje del odio facilita o sostiene la democracia. De hecho, hace lo contrario, vulgarizando el discurso público y desalentando la participación de los grupos oprimidos (Parekh, 2006, p. 219).

\subsection{EL ARGUMENTO DE LENGUAJE DEL ODIO COMO DISCURSO IRRACIONAL}

Un epíteto racial, según Massey, es a lo mejor un nota ruda y discordante, y a lo peor una forma de violencia verbal que desafía los fundamentos más importantes de discurso público. Los igualitarios y los acomodacionistas argumentan que ese discurso irracional evidentemente falla para promover los fines ideales de discurso público y no existe necesidad de ampararlo con protección constitucional (Massey, 1992-1993, p. 169). Por ejemplo, se plantea el caso de que un científico social convirtiera la inferioridad racial en un asunto académico presentado como una prueba científica. Ante esa situación, según Mastuda, las visiones ignorantes, poco documentadas, no necesitan ser escuchadas en un foro académico, pero las visiones impopulares pero académicamente sostenibles si lo deberían. Esas teorías no deberían ser criminalizadas, sino más bien atacadas en un debate publico y abierto (Matsuda, 1989, p. 2365).

Pero el argumento del lenguaje del odio como irracional va más allá. Considera, según Massaro, que este tipo de lenguaje es particularmente seductor y apela predominante o exclusivamente o los instintos no cognitivos (Massaro, 1991, p. 247). El argumento sostendría que esas apelaciones emocionales no aportan nada y deben alejarse del discurso público que debe basarse en una deliberación racional. Frente a esta visión, Karst considera que la eliminación de la parte emocional del discurso público es peligrosa para las minorías y para su discurso de liberación (Karst, 1990, p. 142). 


\subsection{EL ARGUMENTO DEL MAL INTRÍNSECO DEL LENGUAJE DEL ODIO}

Un argumento de defiende los igualitaristas es básicamente que el lenguaje del odio atenta a la igual dignidad de todos los seres humanos. Analizando el artículo 1 de la Ley Fundamental de Bonn ${ }^{17}$, Hoerster se refiere a este concepto de dignidad humana como una fórmula vacía ya que es una cuestión de valoración, no meramente descriptiva, ni puramente normativa, que se convierte en inevitable y decisiva, el decidir cuáles son las formas de libre autodeterminación humanas éticamente legítimas. ${ }^{18}$ Para delimitar este concepto, Eusebio Fernández se refiere a la pregunta kantiana: “¿cuándo o en qué casos la persona es tratada meramente como un medio?"19 En esta línea de especificación, este autor propone tener en cuenta las tradiciones culturales en las que se ha empleado el principio de dignidad humana como valor de cada persona (Fernández García, 2001: 24). Este es un argumento ambivalente en el caso del lenguaje del odio. Por un lado, como afirma Matsuda, la supremacía racial es una de las ideas que hemos colectiva e internacionalmente considerado y rechazado (Matsuda, 1989, p. 2360). De forma parecida, Massaro sostiene que mucha gente siente, aunque no con igual pasión, que podemos y debemos dar menor aprobación a las ideas de Hitler que las de Luther King (Massaro, 1990-1991, p. 239). Frente a estas posiciones, Massey considera que la prueba empírica sugiere que, mientras las ideas de la inferioridad racial pueden ser universalmente condenadas entre gente de buena voluntad e ilustración, están vivas y son abrazadas entre grandes porciones de la población mundial. De hecho, el tema del lenguaje del odio no existiría si las ideas racistas fueran verdaderamente condenadas universalmente (Massey, 1992-1993, p. 171).

Las razones de la igualdad provienen de diversas perspectivas, pero básicamente sostienen que, como afirma Hemmer, el lenguaje del odio daña a sus víctimas, carece de valor y es discriminatorio (Hemmer, 1995, pp. 308-309). Los derechos invocados tienen que ver con la igual dignidad de todos los seres humanos y una coherente política

\footnotetext{
${ }^{17}$ El citado articulo sostiene que "La dignidad humana es intangible".

18 HOERSTER, (2000, p. 102).

19 Eusebio Fernández contesta a la pregunta afirmando "podríamos contestar que cuando se atenta injustificadamente a su autonomía, a su seguridad, a su libertad o a su igualdad. De la misma forma que podríamos responder que se la trata como un fin a la persona humana, es decir, se le reconoce su dignidad, cuando se crean normas e instituciones que respetan y garantizan el ejercicio de los derechos humanos, esto es como señala la Constitución española en su artículo10.1, de los derechos inviolables que son inherentes a la idea de la dignidad de la persona" (Fernández García, 2001, p. 24).
} 
antidiscriminatoria y, en un argumento más sofisticado, en la igual participación de todos en la deliberación pública, donde el lenguaje del odio tendría un efecto silenciador de las visiones de los miembros de las minorías. Tomarse en serio las minorías implica un compromiso público contra la intolerancia que se manifiesta en formas del discurso que niegan la dignidad o la igualdad a los seres humanos, imposibilitando la reciprocidad moral que permite la convivencia en una sociedad civilizada.

\section{CUANDO EL LENGUAJE DEL ODIO Sí ES DELITO. ALGUNOS CASOS JUDICIALES}

El tema de las tradiciones culturales, antes mencionado, es interesante ya que el firme compromiso con la libertad de expresión en los Estados Unidos le ha llevado ratificar con una importante reserva respecto a esta libertad, la Convención Internacional sobre la Eliminación de todas las Formas de Discriminación Racial que en su artículo 4 establece que "Los Estados parte(...) declararán como acto punible conforme a la ley toda difusión de ideas basadas en la superioridad o en el odio racial, toda incitación a la discriminación racial, así como todo acto de violencia o toda incitación a cometer tales actos contra cualquier raza o grupo de personas de otro color u origen étnico, y toda asistencia a las actividades racistas, incluida su financiación." ${ }^{20}$ Esto ha tenido como consecuencia la adopción de legislación penal contra el racismo y la xenofobia en diversos países, que han ido configurando diversos delitos. ${ }^{21}$ También se han dado diversos casos judiciales que han tenido por objeto el lenguaje del odio que merecen ser objeto de análisis.

Uno de ellos se dio en Canadá donde el sr. Keegstra, un profesor de escuela secundaria en Eckville, una pequeña ciudad en Alberta, fue condenado de promover el odio bajo el

\footnotetext{
${ }^{20}$ Adoptada y abierta a la firma y ratificación por la Asamblea General en su resolución 2106 A (XX), de 21 de diciembre de 1965 Entrada en vigor: 4 de enero de 1969, de conformidad con el artículo 19.

${ }^{21}$ Landa Gorostiza explica que "En los países de Europa occidental se puede hacer una división relevante entre el ámbito germánico y Gran Bretaña, por un lado, y por los países latinos y románicos por el otro. Tanto el ámbito germánico como Gran Bretaña son fieles a un "modelo político criminal europeo restringido" caracterizado por el hecho de que además de que el delito de provocación sea la figura central, o bien constituye el único instrumento penal antixenófobos (Gran Bretaña), o bien se ve completado únicamente por figuras apologéticas (ámbito germánico: "mentira de Auschwitz").En los países latinos, por el contrario, dominaría un "modelo político-criminal europeo expandido" que sintetiza de manera acumulativa el modelo estadounidense (agravaciones/cualificaciones) con el europeo (delito de provocación) integrando también figura penales propias de lo que hemos denominado tendencias "expansivas": esto es, delitos de actos de discriminación y figura apologéticas. Los países latinos, en definitiva, contarían con un sistema penal antixenófobos muy variado en cuanto a figuras penales (delito de provocación, agravantes genéricas, tipos cualificados, delitos de actos de discriminación, figuras apologéticas) y con una tendencia más acentuada también a orientar el sentido de la protección hacia la lógica antidiscriminatoria y protectora del principio de igualdad in toto. (Landa Gorostiza, 1999, p. 384).
} 
artículo 319.2 del Código Penal. Se consideró probado que había sistemáticamente denigrado a los judíos y al judaísmo en sus clases. Describía a loa judíos por los siguientes epítetos "traicioneros", "impostores", "comunistas", "secretos", "arteros", "manipuladores" y "engañosos". El enseñaba que el pueblo judío era "bárbaro", "subversivo", "sádico", "materialista", "amante del dinero" y "hambriento de poder". Mantenía que cualquier judío debe ser malvado y que cualquier malvado debe ser judío. No sólo mantenía estas cosas, advertía a sus estudiantes que debe aceptar sus visiones como verdaderas, a no ser que pudieran contradecirlas. Más aun, el esperaba que sus estudiantes repitieran estas nociones en ensayos y exámenes. Si hacían esto, tenían buenas notas. Si no lo hacían, sus notas eran malas. ${ }^{22}$

En la argumentación de la Corte Suprema canadiense, aunque reconoce el valor de la jurisprudencia norteamericana sobre la Primera Enmienda, considera que se demanda una perspectiva particular a la jurisprudencia canadiense donde se ponderen los intereses en cuestión ya que los valores fundamentales en la concepción canadiense de una sociedad libre y democrática sugiere un enfoque que niega que a la propaganda del odio tenga la más alta protección constitucional. Una característica distintiva de Canadá es su compromiso como sociedad multicultural. En este sentido, la sección 27 de la Carta de Derechos Fundamentales establece que dicha Carta debe ser interpretada en una forma consistente con la preservación y mejora de la herencia multicultural de los canadienses. Desde esta perspectiva, el Tribunal argumenta que la propaganda del odio amenaza seriamente el entusiasmo con que el valor de la igualdad es aceptado y es actuado de acuerdo con la sociedad y la conexión con los miembros del grupo minoritario a su comunidad. El multiculturalismo no puede preservarse solo para mejorar si da rienda suelta a la promoción del odio sobre grupos culturales identificables. Dado el vigor con que la propaganda del odio repudia y socava los valores democráticos, y en particular su condena de la visión de que todos los ciudadanos necesitan ser tratados con igual respeto y dignidad así como hacer la participación en el proceso político significativa, es incapaz de ver la protección de esa expresión como integral al ideal democrático tan central como las razones del artículo que protege la

22 Regina v. Keegstra 19903 SCR 697 p. 68. 
libertad de expresión. ${ }^{23}$ Es destacable que el Tribunal utiliza, además de la referencia a la sociedad multicultural, los mencionados argumentos de la igual dignidad de los individuos e igual participación en el debate público.

Uno de los elementos centrales de la Sentencia es la definición de odio y de su relevancia jurídica. El Tribunal establece "el odio se predica sobre la destrucción, y el odio contra grupos identificables, por tanto, crece sobre la insensibilidad, intolerancia y destrucción del grupo minoritario y de los valores de nuestra sociedad. Odio en este sentido es la más extrema emoción que la razón crea; una emoción que, si se ejerce contra los miembros de un grupo identificable, implica que aquellos individuos deben ser despreciados profundamente, desdeñados, negados en su respeto y hechos sujetos de maltrato sobre la base de la afiliación de grupo." ${ }^{24}$ Esta definición supone que va más allá de la antipatía, el Tribunal debe realizar una inferencia del necesario mens rea que tiene una naturaleza subjetiva, lo que es un ejercicio interpretativo que podría tener inciertos resultados. A este respecto, el Tribunal sostiene que "el peligro de inferir impropiamente odio de las declaraciones que se consideran ofensivas no se puedan descartar a la ligera, aunque no cree que la subjetividad inherente en determinar cuando el autor intenta promover el odio, como opuesto a la emoción que comporta un menor grado de antipatía, representan una licencia desenfrenada a extender el delito." ${ }^{25}$ En este sentido, es interesante una consideración que realiza el Tribunal Supremo Canadiense sobre el uso imprudente de este artículo del código penal donde la legislación sobre derechos humanos aparece como una alternativa más atractiva y sólo en casos de recalcitrantes que se dedican a odiar se requerirán ocasionalmente el uso de derecho penal. ${ }^{26}$ Lo relevante del caso es que sitúa la clave en el ejercicio de interpretación del juez de la noción de odio a partir de las declaraciones, donde sólo los casos más extremos merecerán calificación punible.

Otro caso relevante se dio en Francia donde un escritor Soulas publicó en 2000 un libro titulado La colonización de Europa y subtitulado El discurso verdadero obre la

\footnotetext{
${ }^{23}$ Regina v. Keegstra 19903 SCR 697 p. 45-53.

${ }^{24}$ Regina v. Keegstra 19903 SCR 697 p. 56.

${ }^{25}$ Regina v. Keegstra 19903 SCR 697 p. 57.

${ }^{26}$ Regina v. Keegstra 19903 SCR 697 p. 60-61.
} 
inmigración y el Islam. El autor pretende "subrayar particularmente lo que él cree ser la incompatibilidad de la civilización europea con la civilización islámica en una área geográfica concreta." 27 Para justificar su punto de vista realiza una serie de afirmaciones sobre los inmigrantes de origen magrebí y los originarios del Africa subtropical, asociándolos a la delincuencia, al expansionismo islámico y a la francofobia. ${ }^{28}$ Una de las afirmaciones más polémicas aparece en el apartado de soluciones cuando contempla que para remediar lo que él considera ser la colonización de Europa por el tercer mundo, el autor afirma en forma de subtítulo "solamente si estalla una guerra civil étnica podrá hallarse la solución." ${ }^{29}$ Las asociaciones de lucha contra el racismo denunciaron la publicación del libro ante los tribunales basándose en el artículo 24.6 de la Ley de Libertad de Prensa que prohibía la incitación a la discriminación, al odio y la violencia por motivos raciales y religiosos. ${ }^{30}$

Los Tribunales franceses condenaron al autor y éste acudió al Tribunal Europeo de Derechos Humanos por la vulneración del artículo 10 del Convenio. ${ }^{31}$ Este Tribunal consideró que los motivos del Tribunal de apelación francés eran suficientes y pertinentes. Establece en la Sentencia del TEDH, que "en efecto, la Ley de 29 de julio de 18881, y la aplicación que de ella hacen los tribunales internos, constituye un marco estricto para la libertad de expresión. Sin embargo, en las circunstancias de la causa,

\footnotetext{
27 Caso Soulas contra Francia. Sentencia 10 de Julio. TEDH 2008/42 6.

${ }^{28}$ Entre los pasajes del libro se puede destacar: “(..) que la guerra étnica ha comenzado, en forma de "guerrilla urbana larvada”, y que la delincuencia de los jóvenes afro-magrebíes es un medio de conquista de territorios y de expulsión de los europeos al interior del territorio estatal francés"(...) "no se trata de guetos sino de territorios conquistados y colonizados", "Los franceses de pura cepa son expulsados de la zonas con mayoría afro-magrebi", asegurando que la creación de tales "zonas sin Ley" no está relacionada con la miseria puesto que, por el contrario, la población de dichas zonas gozaría de un nivel de vida confortable basado en la economía criminal y el "recurso legal o fraudulento de los alquileres" (...) que la finalidad del Islam en Europa, y para empezar en Francia, es la toma progresiva del poder político y la instauración de una república islámica, consistiendo la primera etapa en la toma de control de cientos de ayuntamientos por partidos islamistas". Caso Soulas contra Francia. Sentencia 10 de Julio. TEDH $2008 / 4214$.

${ }^{29}$ Caso Soulas contra Francia. Sentencia 10 de Julio. TEDH 2008/42 14.

30 El tenor literal de la Ley 29 de julio de 1881 sobre libertad de prensa en Francia en su artículo 24.6 establece que “Aquellos que, por unos de los medios citados en el articulo 23, hayan incitado a la discriminación, el odio o la violencia respecto a una persona o un grupo de personas debido a su origen o pertenencia o su no pertenencia a una etnia, nación, raza, religión determinada, serán castigados con un año de prisión y 300.000 Francos de multa o solamente una de estas dos penas."

${ }^{31}$ El articulo 10 del Convenio Europeo de Derechos Humanos establece "1. Toda persona tiene derecho a la libertad de expresión. Este derecho comprende la libertad de opinión y la libertad de recibir o de comunicar informaciones o ideas, sin que pueda haber injerencia de autoridades públicas y sin consideración de fronteras. El presente artículo no impide que los Estados sometan a las empresas de radiodifusión, de cinematografía o de televisión, a un régimen de autorización previa.

2. El ejercicio de estas libertades, que entrañan deberes y responsabilidades, podrá ser sometido a ciertas formalidades, condiciones, restricciones o sanciones previstas por la ley, que constituyan medidas necesarias, en una sociedad democrática, para la seguridad nacional, la integridad territorial o la seguridad pública, la defensa del orden y la prevención del delito, la protección de la saludo de la moral, la protección de la reputación o de los derechos ajenos, para impedir la divulgación de informaciones confidenciales o para garantizar la autoridad y la imparcialidad del poder judicial.
} 
estos últimos no excedieron el margen de apreciación de que disponían." 32 Esta fue una decisión unánime del Tribunal Europeo que, respecto el trato diferenciado de los tribunales franceses según el perfil de autor enjuiciado, señala que "la comparación que hacen los demandantes con autores extranjeros tales como Taslima Nasreen, Samuel P. Huntington y V.S. Naipul no está fundamentada." ${ }^{33}$

La interpretación de los tribunales franceses, avalada por el TEDH, lo sitúa en un caso claro de incitación al odio e incluso incitación a la violencia, con su apelación a la guerra civil étnica. La caracterización de los musulmanes va más allá del prejuicio y se enmarca en el estigma. De esta forma, además de su igual dignidad, se vería afectada, con este tipo de declaraciones, su participación en el debate público de la democracia francesa. Lo más relevante del caso sería delimitar qué pesa más en la decisión del Tribunal si las acusaciones contra los musulmanes o la solución propuesta de guerra civil étnica. Si en la ratio decidendi se está más cerca de un caso de lenguaje del odio o, más bien, se busca prevenir la incitación a la violencia o los desórdenes públicos.

La diferencia es relevante. En una obra que fue objeto de polémica, Huntington realizaba la siguiente afirmación: "las fronteras del Islam son sangrientas, y también lo son sus áreas y territorios internos" 34 Y más adelante, se refería a que "los choques de civilizaciones son la mayor amenaza para la paz mundial." (Huntington, 1997, p. 386). Según su visión, el Islam es sinónimo de violencia y realiza una matizada predicción de que las civilizaciones chocarán ${ }^{35}$. El Tribunal Europeo de Derechos Humanos consideró

\footnotetext{
${ }^{32}$ En la ratio decidendi el Tribunal Europeo de Derechos Humanos aborda la argumentación seguida por el Tribunal de Apelación francés “Para condenar a los demandantes, El Tribunal de apelación subrayó que las palabras en el libro tenían por objeto provocar en los lectores un sentimiento de rechazo y antagonismo, acrecentado por la imitación del lenguaje militar frente a las citadas comunidades, designadas como el enemigo principal, y llevarlos a compartir la solución recomendada por el autor, la de una guerra de reconquista étnica. El Tribunal de apelación mencionó expresamente en su motivación los extractos del libro en los que se fundaban sus conclusiones, concretamente la aseveración del autor según la cual "solamente si estalla una guerra civil étnica podrá hallarse la solución", afirmación que basada "en la amplificación, previsible, en su opinión, de la delincuencia y las guerrillas territoriales que llevan a cabo las bandas étnicas". El Tribunal de apelación señaló, además, que el libro denunciaba, basándose en distintos hechos, la circunstancias de que jóvenes del extrarradio, pertenecientes a la comunidad magrebí y musulmana, se dedicaban a efectuar "violaciones rituales" de jóvenes blancas por razones de racismo antieuropeo". Caso Soulas contra Francia. Sentencia 10 de Julio. TEDH 2008/42 43-44.

${ }^{33}$ Caso Soulas contra Francia. Sentencia 10 de Julio. TEDH 2008/42 49-50.

34 Huntington justifica sus palabras, afirmando: "a principios de los años noventa, los musulmanes estaban envueltos en más violencia entre grupos que los no musulmanes, y aproximadamente de dos terceras a tres cuartas partes de las guerras entre civilizaciones eran entre musulmanes y no musulmanes" (Huntington, 1997, p.308).

${ }^{35}$ Huntington afirma que "Una guerra a escala planetaria en la que participasen los Estados centrales de las principales civilizaciones del mundo es muy improbable pero no imposible. Una guerra así, lo hemos indicado, podría producirse a partir de la intensificación de una guerra de línea divisoria entre grupos de diferentes civilizaciones, entre los que muy posiblemente se encontrarían musulmanes por un lado y no musulmanes por el otro" (Huntington, 1997, p. 374).
} 
que este autor no era comparable a Soulas. El enfoque de Huntigton es ciertamente más sutil que el de Soulas, pero ambos diseminaban estigmas y prejuicios hacia los musulmanes. $^{36}$

Un caso similar a Soulas, se produjo también en Francia con la publicación del libro de Oriana Fallaci, La rabia y el orgullo donde se encontraban párrafos como los siguientes:

“Porque los Osamas Bin Laden son decenas de miles y no están sólo en los países musulmanes. Están por doquier, y los más aguerridos están precisamente en Europa. La Cruzada al revés dura hace demasiado tiempo, amigo mío.(...) Como sus antepasados ocupan nuestras ciudades, nuestras calles, nuestras casas, nuestras escuelas. Y a través de nuestra tecnología, nuestros ordenadores, nuestros internets, nuestros teléfonos móviles se infiltran en los ganglios de nuestra civilización. Preparan futuras oleadas. Los quince millones de musulmanes que hoy viven en Europa (iquince!) son solamente los pioneros de las futuras oleadas. Y créeme: vendrán cada vez más. Exigirán cada vez más. Pues negociar con ellos es imposible. Razonar con ellos, impensable. Tratarlos con indulgencia o tolerancia o esperanza, un suicidio. Y cualquiera que piense lo contrario es un pobre tonto ${ }^{37}$ (Fallaci, 2002, p. 99).

"Estoy diciendo que nosotros españoles italianos franceses portugueses etcétera no tenemos las condiciones de los americanos: reciente mosaico de grupos étnicos y religiosos, desenvuelto amasijo de miles de lenguas y religiones y culturas, al mismo tiempo abierto a cualquier invasión y capaz de rechazarla. Estoy diciendo que exactamente porque está definida y es muy precisa, nuestra identidad cultural no puede soportar una oleada migratoria compuesta por personas que, de un modo o de otro, pretenden cambiar nuestro sistema de vida. Nuestros principios, nuestros valores. Estoy diciendo que en Italia, en Europa, no hay sitio para los muecines, los minaretes, los falsos

\footnotetext{
${ }^{36}$ En otra obra, Huntington, caracteriza a los hispanos por "la desconfianza en la gente ajena a la familia; la falta de iniciativa, seguridad y ambición; lo poca importancia que se da a la educación y la aceptación de la pobreza como una virtud necesaria para entrar en el cielo" (Huntington, 2004, p.12).

37 Fallaci, 2002, p. 99.
} 
abstemios, el maldito chador y el aún más jodido burka. Y hasta si hubiese, yo no se lo daría." ${ }^{38}$ (Fallaci, 2002, p. 143).

Entre otras expresiones del libro se incluía la siguiente: "Ils se multiplient comme les rats. Se multiplican como las ratas." Sobre lo que, en un libro posterior, afirma "ningún proceso liberticida podrá negar algo de lo que ellos mismos se vanaglorian" (Fallaci, 2004, p. 54) ${ }^{39}$. La autora fue objeto de un juicio en Francia donde diversas asociaciones de lucha contra el racismo la denunciaron solicitando una pena de un año de cárcel, una indemnización y una de ellas pidió que el libro llevara escrita la siguiente frase “¡Atención! ¡Este libro puede ser perjudicial para su salud mental!”. Finalmente no fue condenada por un defecto de forma (Fallaci, 2004, pp. 65-66). La nulidad del proceso fue debida una cuestión procesal (Ligue de Droits de l'Homme (2006): annexe 5), aunque quizá hubiera sido más interesante que un Tribunal hubiera decidido sobre la cuestión de fondo, en especial con el precedente del caso Soulas. ¿Cambia algo sustancialmente en los dos casos? ¿Es un ejercicio de la libertad de expresión de ideas disidentes, políticamente incorrectas, pero legítimas en una sociedad democrática? ¿A partir de qué medida el odio o la ofensa pueden prohibirse jurídicamente? ¿Es suficiente con que el Estado, de forma paternalista, incluya en el libro una referencia a que puede perjudicar su salud mental? ¿O bastaría que recordara que no se puede confundir a los islamistas con los musulmanes?

\section{ALGUNAS REFLEXIONES SOBRE DERECHO, LIBERTAD DE EXPRESIÓN Y LENGUAJE DEL ODIO}

Una de las primeras cuestiones que surgen al aproximarse al estudio del Derecho es la pregunta por sus límites. Frente a la tentación totalitaria de un Derecho omnicomprensivo que regulara todos los ámbitos de la actividad humana, los juristas suelen reflexionar por cuáles son los límites legítimos de intervención estatal en la esfera individual. Desde el liberalismo, se formula una defensa de la intervención legal en casos donde se produzca daño a terceros. Mientras, desde el paternalismo, se defiende la intervención estatal en el caso de daño físico o psíquico, independientemente de la

\footnotetext{
38 Fallaci, 2002, p. 143

${ }^{39}$ Fallaci, 2004, p. 54.
} 
voluntad del sujeto, y el perfeccionismo buscar impedir el daño moral y fomentar las virtudes. Estas concepciones morales pueden inspirar determinadas políticas públicas y, en cada caso, se plantea la cuestión de los límites legítimos del Derecho.

La libertad de expresión tiene un papel fundamental en una sociedad democrática, está vinculada a la libertad de conciencia y libertad ideológica y es un elemento esencial para el control de los gobernantes. Desde este punto de vista, los límites a la libertad de expresión son considerados como sospechosos. El extremo de esta visión es la interpretación que hacen algunos de que la Primera Enmienda de la Constitución norteamericana establece para la libertad de expresión un derecho absoluto. Frente a esta posición, cabe considerar que existen límites legítimos a la libertad de expresión cuando se producen determinados conflictos con otros derechos fundamentales. Es habitual considerar que la incitación a la violencia o la amenaza de desordenes públicos no merece protección constitucional. Más allá, precisamente la polémica se establece si los límites legítimos de la intervención estatal comprenden las expresiones del odio.

Existe una tradicional distinción jurisprudencial sobre el tratamiento de los hechos y de las opiniones. Respecto de los hechos, se sigue el criterio del caso New York v. Sullivan, donde es exigible una contrastación diligente de la información, pero no necesariamente su veracidad, según la traslación del Tribunal Constitucional español de la doctrina de la actual malice. Respecto de las opiniones, el criterio es más amplio, en la conocida expresión de la Corte Suprema "bajo la Primera Enmienda no existe tal cosa como una idea falsa". ${ }^{40}$ Existe una importante influencia del respeto a la autonomía moral que se encuentra la filosofía liberal de Stuart Mill y, especialmente, la consideración que no es la función de los jueces y tribunales proscribir ideas del debate público, habiendo determinado su verdad o falsedad. Sin embargo, el caso del lenguaje del odio pone cuestión esta doctrina y replantea el papel de los jueces respecto de los límites de la libertad de expresión. Frente a los argumentos liberales esgrimidos, la afirmación de la igual dignidad de los seres humanos debe tener una traslación jurídica

\footnotetext{
${ }^{40}$ Gertz v. Robert Welch Inc. 418 U.S. 323, 339-40 (1974).
} 
en la protección de los miembros de las minorías de los ataques mediante las expresiones que los vilipendian y denigran.

Frente al argumento que permitir esas expresiones es el coste de la libertad, frente a modelos autoritarios, cabe plantear que el lenguaje del odio produce daño, a individuos concretos y a colectivos específicos. La misoginia, el racismo, el antisemitismo, la homofobia, la xenofobia y otras formas del alterofobia tienen diversos mecanismos para producir víctimas y crear daños. Algunos de esos mecanismos tienen que ver con uso del lenguaje. El activismo ha de llevar a una "revolución cultural", como propone Young, para transformar estigmas, prejuicios y estereotipos. También es importante el papel de una educación en derechos humanos, como un camino para fortalecer las virtudes públicas del ciudadano. Pero el Derecho debería intervenir en los casos de "recalcitrantes odiadores", en la terminología del caso Keegstra, cuando se refiere al odio como "la más extrema emoción que la razón crea; una emoción que, si se ejerce contra los miembros de un grupo identificable, implica que aquellos individuos deben ser despreciados profundamente, desdeñados, negados en su respeto y hechos sujeto de maltrato sobre la base de la afiliación de grupo." ${ }^{41}$ Es una fehaciente y explícita negación de la dignidad humana a los miembros de una minoría.

Un compromiso con la igualdad debe traducirse, si se concibe la democracia como un debate entre libres e iguales, en no permitir el discurso a aquellos que no siguen las reglas de juego, ya que no respetan la igual dignidad de otros participantes en el debate y dificultan la igual participación de los miembros de las minorías. Un compromiso con la libertad supone que existe un peligro mayor en censurar opiniones que en permitirlas ya que, en última instancia, los individuos tienen capacidades suficientes para calibrar el discurso del odio. La caracterización como un dilema moral entre libertad e igualdad supone que, en la elección, existirá un bien relevante que será sacrificado, sea cual sea la solución adoptada. Desde este punto de vista, estas situaciones suponen una ponderación que deben realizar los jueces según las circunstancias de cada caso. El discurso en cuestión debe suponer una vulneración de la igual dignidad de los seres

\footnotetext{
${ }^{41}$ Regina v. Keegstra 19903 SCR 697 p. 56.
} 
humanos profunda y relevante que justifique adecuadamente su prohibición. Existe el peligro de la pendiente resbaladiza que supondría, por esta vía, eliminar todo discurso ofensivo, molesto o disidente. Algo que una democracia no debe permitirse, en su inherente vinculación con el pluralismo y el debate público robusto.

Que existan algunos casos difíciles no debe hacer perder de vista que existen casos donde es legítimo que intervenga el Derecho, en la línea del standard de los "recalcitrantes odiadores". Las vías de fundamentación de estas medidas pueden ser perfeccionistas -como mal intrínseco-, paternalistas -produce los daños físicos o psíquicos- o incluso liberales -con una adecuada definición al caso del daño a terceros-. Es interesante el caso donde se permitía la publicación de un libro añadiendo en la solapa que "puede dañar su salud mental". Esa es una medida de excesivo paternalismo estatal, pero indica el papel que tiene que tener la educación y los medios de comunicación que permitan discernir por si mismos a los individuos sobre determinados discursos contrarios a los derechos humanos. La prohibición es una medida extrema del Derecho que requiere de su justificación para los casos graves. Pero existe una diferencia clara entre la no prohibición y el fomento. Ese es el camino de la "revolución cultural" para connotar los discursos de odio -como origen de los estigmas, estereotipos y prejuicios a los miembros de las minorías- como un discurso filosófica, política y moralmente inaceptable en una democracia. Esto debe ser asumido por la inmensa mayoría de los ciudadanos.

Si la alternativa es entre que Oriana Fallaci vaya a la cárcel mientras se prohíbe su libro $y$, por otro lado, se repliquen sus argumentos y se la califique de racista y xenófoba, parece que habría más razones para la libertad. Sin embargo, existen situaciones donde el discurso va más allá, es una vejación grave, un insulto, una ofensa seria a la igual dignidad humana, dando en ese caso más razones a la igualdad. Entonces es cuando está justificado que intervenga el Derecho. Como un dilema entre libertad e igualdad, el caso del lenguaje del odio muestra los límites legítimos que deberían tener el Derecho, la democracia y el pluralismo. Como advirtió Popper con su célebre paradoja: "la tolerancia ilimitada debe conducir a la desaparición de la tolerancia. Si extendemos la tolerancia ilimitada aun a aquellos que son intolerantes; si no nos hallamos preparados 
para defender una sociedad tolerante contra las tropelías de los intolerantes, el resultado será la destrucción de los tolerantes y, junto con ellos, de la tolerancia." (Popper, 1989, p. 512).

\section{REFERENCIAS BIBLIOGRÁFICAS}

Abrams, F. (1992). Hate speech: The present implications of a historical dilemma. Villanova Law Review, 37, 743-756.

Atienza, M. (2002). Los límites de la interpretación constitucional. De nuevo sobre los casos trágicos en Vázquez, R. (comp.), Interpretación y decisión judicial (pp. 187-213). México: Fontarama.

Austin, J. L. (2017). Cómo hacer cosas con palabras. Barcelona: Paidós. Traducción de Genaro Carrió y Eduardo A. Rabossi.

Balkin, J.M. (1998). The meaning of constitutional tragedy. En Eskridge Jr., W. y Levinson, S., Constitutional stupidities. Constitutional tragedies, New York University Press, $121-128$.

Bernal del Castillo, J. (1998). La discriminación en Derecho Penal. Granada: Comares. Brink, D. O. (2001). Millian principles, Freedom of expression, and hate speech. Legal Theory, 7, 119-157.

Butler, J. (2009). Lenguaje, poder e identidad. Madrid, Síntesis, traducción de Javier Saez y Beatriz Preciado.

Delgado, R. (1982). Words than wound: A tort action for racial insults, epithets and name-calling. Harvard Civil Rights, Civil Liberties Law Review, 17, 133-181.

Delgado, R. y Stefanic, J. (1995-1996). Ten arguments against hate-speech regulation: How valid? Nothern Kentacky Law Review, 23, 475.

Dworkin, R. (1996). Freedom's Law. Harvard University Press.

Fiss, O. (1996). El efecto silenciador de la libertad de expresión. Isonomía , 4, 17-27. 
Fallaci, O. (2002). La rabia y el orgullo. Madrid: La esfera de los libros. Traducción de Miguel Sánchez.

Fallaci, O. (2004). La fuerza de la razón. Madrid: La esfera de los libros. Traducción de José Manuel Vidal.

Fernández García, E. (2001). Dignidad humana y ciudadanía cosmopolita. Madrid: Dykinson.

Hemmer, J. Jr (1995). Hate speech. The egalitarian/libertarian dilemma. Howard Journal of Communications, 5(4), 307-330.

Hoerster, N. (2000). Acerca del significado del principio de la dignidad humana en Hoerster, N. En defensa del positivismo jurídico. Barcelona: Gedisa. Traducción de Ernesto Garzón Valdés.

Hylton, K. N. (1996). Implications of Mill's Theoy of liberty for the regulation of hate speech and hate crimes, University of Chicago Law School Roundtable, 3, 35- 57.

Huntington, S. (1997). El choque de las civilizaciones y la reconfiguración del orden mundial. Barcelona: Paidós. Traducción de José Pedro Tosaus Abadía.

Huntington, S. (2004). El reto hispano, Foreign Policy, 1-12.

Ingrer, S. (1984). Marketplace of ideas: A legitimizing myth. Duke Law Journal, 1, 1-91.

Karst, K. L. (1990). Boundaries and reasons: Freedom of expression and the subordination of groups, University of Illinois Law Review, 1, 95-149.

Lariguet, G. (2008). Dilemas y conflictos trágicos. Lima: Palestra.

Lawrence, F. (1992-1993). Resolving the hate crimes/hate speech paradox: Punishing bias crimes and protecting racist speech, Notre Dame Law Review, 68, 673- 721.

Ligue de Droits de l'Homme, Rapport annuel 2006, annexe 5

Masaro, T. M. (1990-1991). Equality and freedom of expression: The hate speech dilemma, William and Mary Law Review, 32, 211-265. 
Massey, C., (1992-1993). Hate speech, cultural diversity and the foundational paradigms of free expression, UCLA Law Review, 40, 103-197.

Matsuda, M. J. (1988-1989). Public response to racist speech: considering the victims story, Michigan Law Review, 87, 2320- 2381.

Parekh, B. (2006). Hate speech. Is there a case for banning? Public policy research, 12(4), 213-223.

Popper, K. (1989). La sociedad abierta y sus enemigos. Barcelona: Paidós. Traducción de Eduardo Loedel.

Post, R. (1990-1991). Racist speech, democracy and the first amendment, William and Mary Law Review, 32, 267-327.

Raz, J. (1988). Morality of freedom, Oxford, Claredon Press.

Rico, M. (2004). Ladrones de palabras. Letras Libres, 14-15.

Rosenfeld, M. (2003). Hate speech in Constitutional jurisprudence: A comparative analysis, Cardozo Law School, Working Paper series 41.

Sadurski, W. (1999). Freedom of speech and its limits. Dordrecht: Boston.

Saavedra, M. (2006). El lenguaje del odio en la jurisprudencia del Tribunal Constitucional Español, Persona y Derecho, 55, 547-576.

Sunstein, C. R. (1987-1988). Beyond the republican revival. Yale Law Journal, 97, 15391590.

Stuart Mill, J. (1991). Sobre la libertad. Madrid: Espasa Calpe. Traducción de Cristina García Gay.

Young, I. M., (2000) La justicia y la política de la diferencia. Madrid: Cátedra. Traducción de Silvina Álvarez. 